\title{
Organization of Cortical Cytoskeleton of Cultured Chromaffin Cells and Involvement in Secretion as Revealed by Quick-Freeze, Deep-Etching, and Double-Label Immunoelectron Microscopy
}

\author{
Takao Nakata and Nobutaka Hirokawa \\ Department of Anatomy and Cell Biology, School of Medicine, University of Tokyo, 7-3-1, Hongo, Tokyo, Japan, 113
}

\begin{abstract}
We have studied the organization of the cytoskeleton in both unstimulated and stimulated cultured chromaffin cells, as well as its relationship with their secretory process by exocytosis. We found the spatial heterogeneity in the intensity of cortical rhodamine-phalloidin staining within a cell. The overall staining pattern or intensity was minimally altered after stimulation, although dopamine- $\beta$-hydroxylase (DBH) antigen, a marker for the chromaffin granule membrane, was exposed preferentially on the plasma membrane areas with lower intensity of rhodamine-phalloidin staining. Using the quick-freeze, deep-etch technique, we found the heterogeneity in the organization of cortical cytoskeletal networks-some regions have actin filament bundles running parallel to the plasma membrane interspersed between granules and the plasma membrane, while others have few actin filaments beneath the plasma membrane before stimulation. Actin filaments were rarely observed in the inner cytoplasm. We did not observe the overall change in its organization after stimulation. Double-label immunogold EM using anti-DBH antibody and anti-actin antibody combined with statistical analysis showed that (1) DBH was exposed on the plasma membrane preferentially where actin was sparse after stimulation (significant at $<0.1 \%$ ), although (2) regions having sparse actin were not always the sites for DBH exposure, and (3) the cortical actin zone was sometimes disrupted at the DBH-exposed sites after stimulation. The present data suggested that (1) secretion is related to heterogeneous organization of cortical cytoskeleton after stimulation and (2) massive synchronized reorganization of the cytoskeleton in the whole cell is not necessary for secretion, although small changes of the cytoskeleton might occur under local regulation at each exocytotic site at the moment of the release.
\end{abstract}

Neurons and neuroendocrine cells secrete their transmitters and hormones by exocytosis after stimulation. This process involves the translocation of secretory vesicles to the plasma membrane,

\footnotetext{
Received Sept. 11, 1991; revised Jan. 3, 1992; accepted Jan. 9, 1992.

This work was supported by a special grant to N.H. from the Ministry of Science and Education in Japan and a grant to N.H. from the Naito Foundation. We thank Dr. H. Sakai for use of the spectrofluorometer, and Dr. T. Kobayashi and Dr. A. Takemura for advice on statistical analysis.

Correspondence should be addressed to Takao Nakata at the above address. Copyright C 1992 Society for Neuroscience $0270-6474 / 92 / 122186-12 \$ 05.00 / 0$
}

attachment and fusion of the two membranes, and release of the vesicle contents (Burgoyne et al., 1982; Sontag et al., 1988). Adrenal chromaffin cells, which release catecholamine by exocytosis on stimulation, have been a good model system for the study of this process since the successful development of primary culturc (Waymire et al., 1983; Livett, 1984). Rccent studies have suggested the involvement of calpactin I in the process of attachment of vesicles and the plasma membrane (Durst and Creutz, 1988; Ali et al., 1989; Nakata et al., 1990).

It has been proposed that the subplasmalemmal cytoskeleton might play a role in the process of the translocation prior to the exocytotic fusion (Aunis and Bader, 1988). Immunofluorescence studies have revealed that a number of cytoskeletal proteins localize in the cortex of chromaffin cells, such as actin, fodrin, caldesmon, vinculin, and gelsolin (Burgoyne et al., 1986; Aunis and Bader, 1988). $\mathrm{Ca}^{2+}$-dependent association of chromaffin granules and cytoskeletal proteins was shown in vitro (Fowler and Pollard, 1982; Burgoyne et al., 1986). Treatment of permeabilized chromaffin cells with anti-fodrin antibodies prevented the release of catecholamine (Perrin et al., 1987). On the basis of these data, models have been proposed that on stimulation, the barricrs of cytoskcletal networks will be disrupted prior to the exocytosis of chromaffin granules (Geisow and Burgoyne, 1987; Trifaro and Fournier, 1987; Aunis and Bader, 1988).

However, the cytoskeletal architecture beneath the plasma membrane in the secretory cell has not been visualized in detail. To examine whether a dramatic reorganization of the cytoskeleton is actually necessary for secretion as described in the models, we used several approaches. First, to investigate the relationship of actin organization and its secretion, we performed double-label experiments with rhodamine-phalloidin and anti-dopamine- $\beta$-hydroxylase (anti-DBH) antibody. DBH is a marker of chromaffin granules that has been used to detect exocytosis from chromaffin cells at LM and EM levels (Wildman et al., 1981; Lingg et al., 1983; Patzak et al., 1984; Patzak and Winkler, 1986; Sontag et al., 1988). Second, the three-dimensional architecture of the cytoskeleton in the cytoplasm and just beneath the plasma membrane in cultured chromaffin cells was studied using the quick-freeze, deep-etch technique (Heuser and Salpeter, 1979; Hirokawa and Heuser, 1981; Nakata and Hirokawa, 1987). Third, to investigate the relationship between cortical actin organization and each exocytotic site, we performed double-label immuno-EM on frozen ultrathin sections of the cells before and after stimulation, using anti-actin and anti-DBH antibodies. 


\section{Materials and Methods}

Isolation and culture of chromaffin cells. Chromaffin cells were isolated from bovine adrenal medulia and cultured as described previously (Kumakura et al., 1986; Nakata et al., 1990). Some cells were purified further by Percoll (Pharmacia) density gradient centrifugation (Livett, 1984) before plating. All the experiments were performed with the cells in culture for 3-10 d.

Quick-freeze, deep-etch electron microscopy of cultured chromaffin cells. Cultured chromaffin cells were washed with Locke's solution (140 $\mathrm{mm} \mathrm{NaCl}, 4.7 \mathrm{~mm} \mathrm{KCl}, 1.2 \mathrm{~mm} \mathrm{KH}_{2} \mathrm{PO}_{4}, 1.2 \mathrm{~mm} \mathrm{MgSO}_{4}, 11 \mathrm{~mm}$ glucose, $0.546 \mathrm{~mm}$ ascorbate, $15 \mathrm{~mm}$ HEPES, $\left.2 \mathrm{~mm} \mathrm{CaCl}_{2}, \mathrm{pH} 7.5\right)$ and quick-frozen as described previously (Nakata et al., 1990). For stimulation, Locke's solution containing $100 \mu \mathrm{M}$ carbachol was added before freezing. For digitonin permeabilization, cells were incubated with 20 $\mu \mathrm{M}$ digitonin in $\mathrm{KHMgE}$ buffer $(70 \mathrm{~mm} \mathrm{KCl}, 30 \mathrm{~mm}$ HEPES, pH 7.2, $5 \mathrm{mM} \mathrm{MgCl}_{2}, 2 \mathrm{~mm}$ EGTA, $10 \mu \mathrm{M}$ taxol, $1 \mathrm{~mm}$ phenylmethylsulfonyl fluoride, $10 \mu \mathrm{M}$ leupeptin) for $10 \mathrm{~min}$ at room temperature before freezing (Hirokawa and Heuser, 1981). Some cells were further incubated with $2 \mathrm{mg} / \mathrm{ml}$ chicken myosin subfragment 1 (S1) for $30 \mathrm{~min}$ at room temperature for S1 decoration (Hirokawa et al., 1982; Nakata and Hirokawa, 1987).

Quick-frozen samples were freeze-fractured, deep-etched, and rotaryreplicated as described previously (Heuser and Salpeter, 1979; Nakata et al., 1990).

Double-label fluorescence microscopy and confocal laser scan microscopy. Cells on a coverslip were washed with Lock's solution and fixed in $3 \%$ paraformaldehyde-PBS for $1 \mathrm{hr}$. Some cells were stimulated with $100 \mu \mathbf{M}$ carbachol before fixation. After rinsing three times in PBS, the cells were treated with $5 \%$ skim milk-PBS for $10 \mathrm{~min}$. They were incubated with anti-DBH antibody (Eugene Tech International, Inc., Allendale, NJ). The cells were again washed with PBS and incubated with fluorescein isothiocyanate-conjugated goat antibodies to rabbit IgG (Cappel Laboratories, Cochranville, PA). After vigorous washing, the cells were permeabilized with $0.1 \%$ Triton-PBS for $10 \mathrm{~min}$. They were incubated with rhodamine-phalloidin (Wako Pure Chemicals, Osaka, Japan) and washed with PBS before mounting. Cells were viewed on a Zeiss confocal laser scan microscope. In Figures 1 and 2, relative intensity of the luminescence has been color encoded, with the more intense light indicated by longer-wavelength colors.

Fluorescence intensity. Chromaffin cells were purified with Percoll density gradient and cultured in floating medium to avoid the growth of contaminating fibroblasts (Waymire et al., 1983). Cells $\left(1 \times 10^{6}\right)$ were fixed and stained with rhodamine-phalloidin as described above. After final wash with PBS by centrifugation, rhodamine-phalloidin bound to the cells was then extracted with $400 \mu \mathrm{l}$ of ethanol. After brief centrifugation, the supernatants were excited at $544 \mathrm{~nm}$; fluorescence emission was read at $575 \mathrm{~nm}$ using a Hitachi $650-10$ s fluorescence spectrophotometer (Bernstein and Bamburg, 1989).

Double-label immunostaining on cryo-ultrathin sections. Cryo-ultrathin sections of cultured chromaffin cells before and after stimulation were prepared as described previously (Tokuyasu, 1980; Nakata et al., 1990). After blocking with 10\% normal goat serum, the sections were incubated with rabbit anti-DBH antibody and then with mouse monoclonal antibody to actin (Amersham International, Amersham, UK). They were washed extensively with PBS followed by incubation with the 10 nm colloidal gold-labeled goat anti-rabbit IgG plus 5 Inn colloidal gold-labeled goat anti-mouse IgM (Janssen Life Science, Beerse, Belgium) in Tris-buffered saline at $\mathrm{pH}$ 8.2. The sections were fixed and mounted in methylcellulose following the method of Tokuyasu (1980).

Quantitative analysis of immunogold labeling. Cells were stimulated with $100 \mu \mathrm{M}$ carbachol for $30 \mathrm{sec}$. They were processed for double-label immuno-EM as described above. Sections were examined with a JEOL 1200 EX electron microscope (JEOL USA, Peabody, MA). For counting actin and DBH labels along the plasma membrane, negatives were printed at $100,000 \times$ magnification. The plasma membrane area in contact with the culture medium was chosen for analysis. The plasma membrane was divided into $200-\mathrm{nm}$-long sections. The number of $10 \mathrm{~nm}$ labels (DBH) in each section was counted. Number of $5 \mathrm{~nm}$ labels (actin) in each section was counted if they existed between the plasma membrane and the nearest chromalfin granule. We counted 708 sections and classified them into nine groups according to the number of actin and DBH labels (see Table 2). The association of the two variables (actin and $\mathrm{DBH}$ labels/section) was tested by the $\chi^{2}$ test of independence.

Determination of catecholamine secretion. Cells were washed with
Locke's solution and stimulated with $100 \mu_{\mathrm{M}}$ carbachol for $3 \mathrm{~min}$ in the solution. Catecholamine release was determined by removal of buffer from wells, which was treated with $0.1 \mathrm{vol}$ of $50 \%$ trichloroacetic acid (TCA) and centrifuged for $15 \mathrm{~min}$ at $15,000 \times \mathrm{g}$ before assaying for total catecholamine by fluorometrically using a modification of the trihydroxyindole method (Anton and Sayre, 1962) (SRL Co., Tokyo). Total catecholamine remaining within the cell was determined after release of catecholamine by sonication of the cells in 5\% TCA.

\section{Results}

\section{Distribution of actin and exocytotic sites at LM level}

We examined the relationship between the sites of exocytosis and actin organization at the LM level. Actin filaments were stained with rhodamine-phalloidin. DBH was a marker for the inner surface of secretory granule membranes, which is known to be inserted into the plasma membrane during exocytosis (Wildman et al., 1981; Lingg et al., 1983). We incubated with anti-DBH antibody before permeabilization of the cells in order to detect the DBH exposed on the plasma membrane. Antibody to DBH did not stain unstimulated cells (Fig. 1a), while DBH staining was observed on the cell surface of stimulated cells (Fig. $1 c, e, g)$. We used confocal laser scan microscopy, which enabled us to analyze the relationship betwecn the two stains on a ccrtain section precisely without interference of the overlap of the fluorescence along the depth of the cells. In Figure 1, the sections were cut at the middle of the cell, approximately $10 \mu \mathrm{m}$ from the coverslip.

In resting cells, rhodamine-phalloidin stained the cell periphery unevenly, which suggested that the organization of cortical actin filaments is not uniform before agonist stimulation (Fig. 1b).

After stimulation, we found that DBH was exposed on the cell surface where the intensity of rhodamine-phalloidin staining is relatively lower. There were two different types of DBH staining after stimulation: focal patches and relative diffuse cell surface staining. At $15 \mathrm{sec}$ after stimulation, $60.3 \pm 7.7 \%( \pm \mathrm{SD})$ of the cells showed focal DBH staining. We found that the intensity of rhodamine-phalloidin was lower at the DBH-exposed sites than the average intensity of its staining in the wholc cell periphery in $72.3 \pm 7.7 \%( \pm \mathrm{SD})$ of these cells. At $30 \mathrm{sec}$ after stimulation, $33.5 \pm 12.1 \%( \pm \mathrm{SD})$ showed focal DBH staining. The intensity of rhodamine-phalloidin was low at the DBHexposed sites in $67.7 \pm 2.8 \%( \pm \mathrm{SD})$ of these cells (experiments were repeated three times on three different cultures of chromaffin cells). It was difficult to state the relationship between the two stains when the cells showed relatively diffuse DBH staining. Figure $1 c-g$ shows typical examples of the cells showing focal DBH staining $30 \mathrm{sec}$ after stimulation. The reason for two different $\mathrm{DBH}$ staining patterns is unknown, but diffuse $\mathrm{DBH}$ staining on the cell surface might be the result of activation of different sites in a cell at different times from stimulation to fixation. We also noticed that regions with lower rhodaminephalloidin intensity are not always the sites of DBH exposure (Fig. 1).

To test whether the inverse correlation between the surface DBH staining and rhodamine-phalloidin staining holds in the whole cells after stimulation, we cut serial confocal sections through the cells. Figure 2 is a typical example of 12 serial confocal sections of the same cell with a focal DBH staining after stimulation. Sections were cut with $1 \mu \mathrm{m}$ intervals from the bottom to the top of the cell (Fig. $2 A-L$ ). The arrowhead in $A$ shows phalloidin staining of the stress fibers of the nearby fibroblast, indicating that the section in $A$ is at the bottom of 

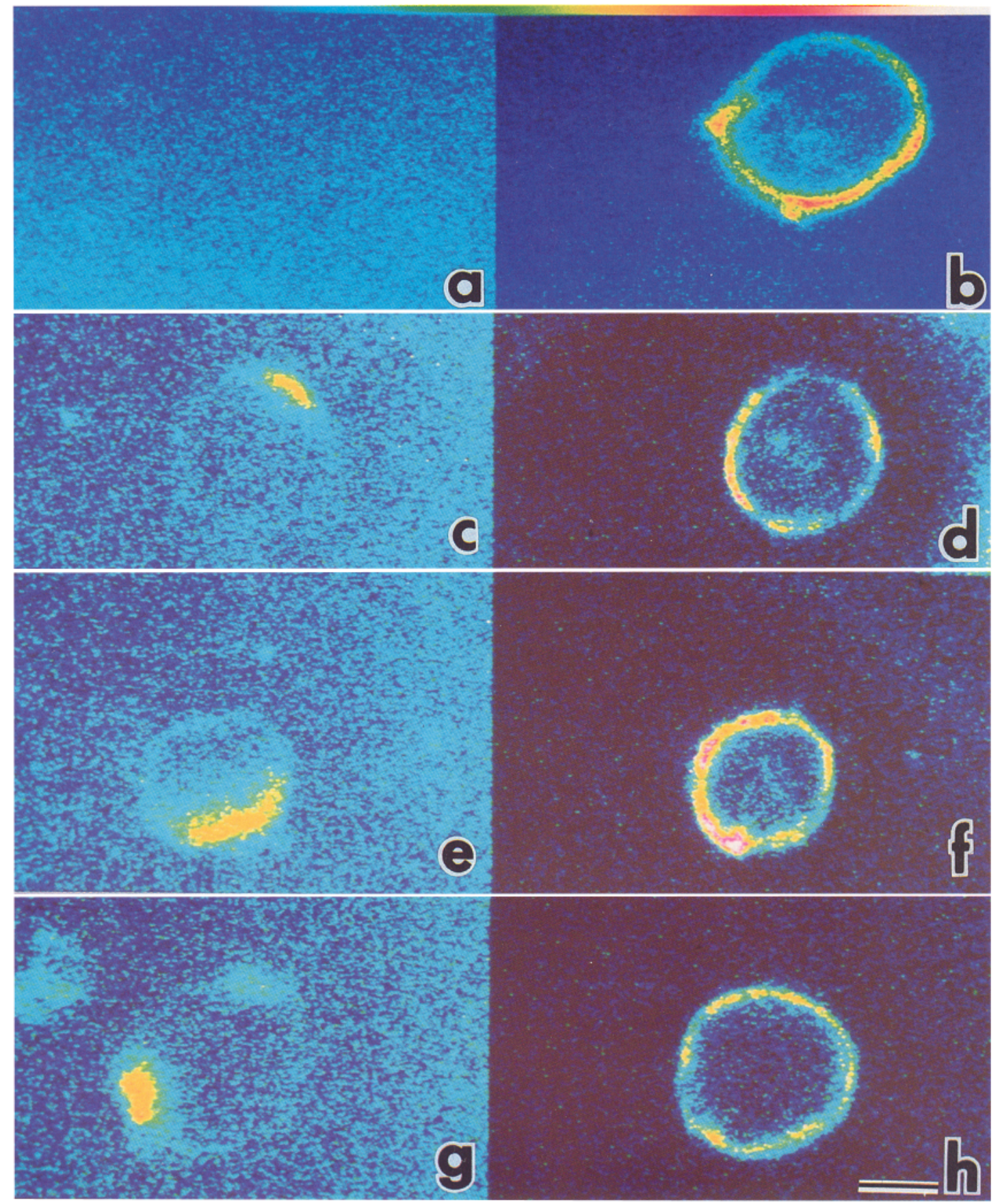

Figure 1. Confocal laser scan microscopy of cultured chromaffin cells double labeled with anti-DBH antibody ( $a, c, e$, and $g$ ), and rhodaminephalloidin $(b, d, f$, and $h)$. Cells before stimulation have no surface $\mathrm{DBH}$ staining $(a)$, while the intensity of peripheral rhodamine-phalloidin staining is not uniform $(b) . c-h$, Typical examples of the cells that show focal DBH staining $(c, e$, and $g)$. Note that areas with intense DBH staining show lower intensity of rhodamine-phalloidin staining. Scale bar, $10 \mu \mathrm{m}$.

the cell. Figure $2 a-l$ shows the surface DBH staining corresponding to the rhodamine-phalloidin staining of $A-L$. This micrograph shows that the area with the surface DBH staining had relatively lower actin filament content within a whole cell.

We performed the double staining at various times $(5 \mathrm{sec}, 15$ $\mathrm{sec}, 30 \mathrm{sec}, 1 \mathrm{~min}$, and $3 \mathrm{~min}$ ) after stimulation, but the total F-actin staining did not change significantly after stimulation. To quantify this result, we measured the fluorescence intensity of rhodamine-phalloidin bound to the cells $30 \mathrm{sec}$ after stimulation. This method has been shown to be well correlated with
DNase I inhibition assay (Bernstein and Bamburg, 1989). Intensity of rhodamine-phalloidin $30 \mathrm{sec}$ after stimulation was $106.6 \pm 1.5 \%( \pm \mathrm{SD} ; n=3)$ of that of control resting cells.

\section{Quick-freeze, deep-etch view of cortical cytoskeleton}

As we found the heterogeneity in cortical actin staining in both unstimulated and stimulated cells, we examined the organization of the cortical cytoskeleton in these areas before and after stimulation by quick-freezing.

Unstimulated cells. Chromaffin cells on collagen gels were 


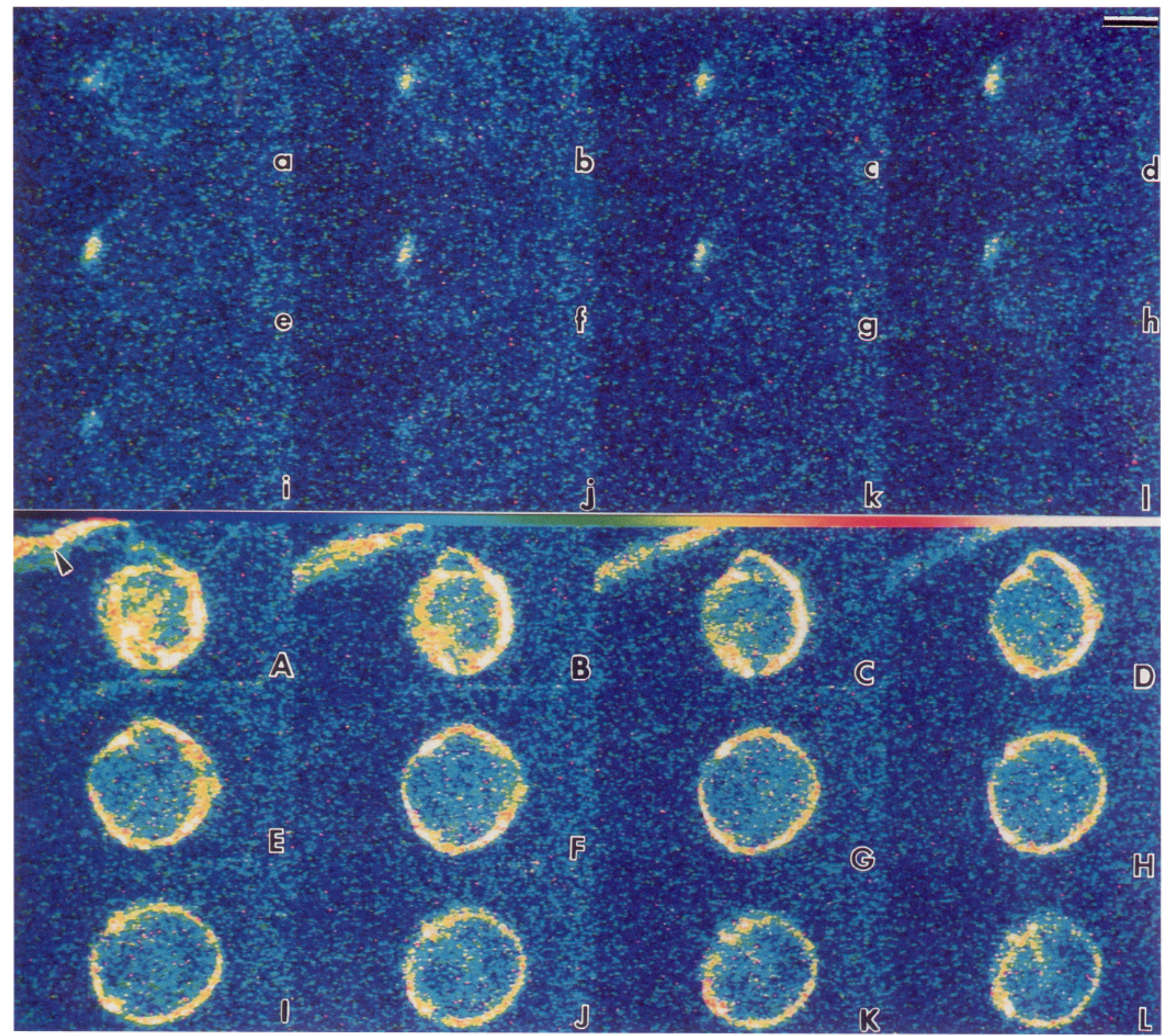

Figure 2. Serial sections ( $1 \mu \mathrm{m}$ thickness) of a cultured chromaffin cell after stimulation by confocal laser scan microscopy. The cell was double labeled with rhodamine-phalloidin $(A-L)$ and anti-DBH antibody $(a-l)$. The cell was sectioned from the bottom $(A, a)$ to the top $(L, l)$ of the cell. The arrowhead in $A$ shows the stress fiber of the nearby fibroblast. Note the inverse correlation between the surface DBH staining and rhodaminephalloidin staining. Scale bar, $10 \mu \mathrm{m}$.

quick-frozen without chemical fixation. Because the existence of soluble proteins makes it difficult to observe filamentous structures clearly in the fresh samples (Nakata et al., 1990), the cells were extracted with digitonin. In the extracted cells, fine strands (5-7 $\mathrm{nm}$ in diameter) between chromaffin granules were observed (Fig. $3 a$ ). However, filamentous structures were poorly developed in the inner cytoplasm in general (Fig. 3b). Actin filaments were rarely observed in this area. Microtubules ran through the cytoplasm and were often associated with chromaffin granules via fine filaments $(7-8 \mathrm{~nm}$ in diameter) (Fig. $3 d$ ).

Nine nanometer filaments running parallel to the plasma membrane were the main component of the subplasmalemmal cytoskeleton (Fig. 4a). S1 decoration showed that these filaments were actin filaments (Fig. 4b). Actin filaments formed a network with some fine filaments other than actin filaments between the plasma membrane and secretory granules (Fig. $4 a$ ). In some areas, they formed prominent bundles (Figs. $3 b, 4 c$ ). In Figure $4 c$, actin binding proteins might be competitively extracted in the presence of S1 (Nakata and Hirokawa, 1987).

There were areas where only few actin filaments were observed between chromaffin granule and plasma membrane (Fig. $3 a, c)$. In these areas, some chromaffin granules were associated with plasma membrane via fine filaments (Fig. $3 c$ ). These filaments ( $\sim 29.2 \mathrm{~nm}$ in length) were much longer than the strandlike structures $(\sim 10 \mathrm{~nm})$ in the stimulated cells we reported previously (Nakata et al., 1990).

Stimulated cells. In the previous study, we showed some chro- 

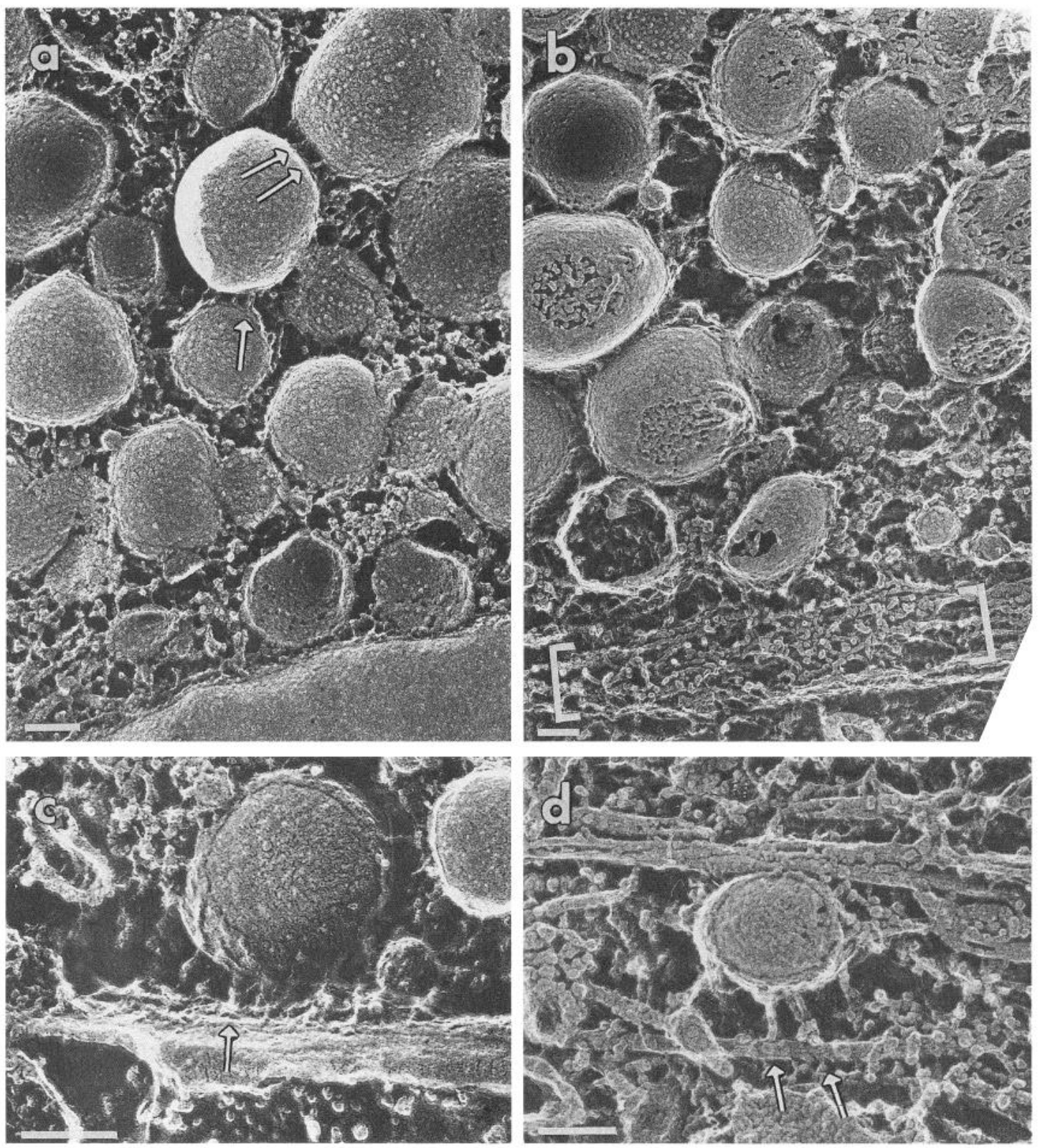

Figure 3. Digitonin-permeabilized unstimulated cells. a, Arrows indicate the associations between the adjacent chromaffin vesicles. Plasma membrane was slightly obliquely fractured. $b$. The subplasmalemmal cytoskeletal network is thick in this area (brackets), while filamentous structures are less well developed in the inner cytoplasm. $c$, The arrow indicates the associations between chromaffin granule and plasma membrane. In $b$ and $c$, plasma membrane was perpendicularly fractured, and outer cellular space (which was filled with culture medium) is seen outside the plasma membrane. $d$, Inner cytoplasm at high magnification. Granules were often associated with microtubules via fine filaments (arrows). Scale bars, $0.1 \mu \mathrm{m}$.

maffin granules to be closely associated with the plasma membrane and exocytotic $\Omega$-shape by quick-freezing of stimulated cells without chemical fixation (Nakata et al., 1990). To observe the cortical cytoskeleton clearly, we chemically permeabilized the cells after stimulation and then quick-froze them. As observed in the unstimulated cells, the filamentous structures were not well developed between the granules in the inner cytoplasm (Fig. 5a,b). Figure 5, $a$ and $b$, shows the subplasmalemmal area of digitonin-permeabilized cells $30 \mathrm{sec}$ after stimulation. In Figure $5 a$, actin-based networks were well developed in the cortical area, and secretory granules resided inside the networks. In Figure $5 b$, only a few actin filaments were observed in the cortical area, and fine filaments (arrows) thinner than actin filaments were found just under the plasma membrane.

We did not observe any significant changes in the organization of the cytoskeleton in both the inner cytoplasm and the cortical cytoskeleton after stimulation. We permeabilized the cells at various times (immediately, $5 \mathrm{sec}, 15 \mathrm{sec}, 30 \mathrm{sec}, 1 \mathrm{~min}$, and 3 min) after stimulation. To avoid the influence of permeabilization, we also first fixed and then permeabilized the cells in some preparations. Because chromaffin cells continue to secrete catecholamine dramatically for $20 \mathrm{sec}$ in the continued presence of ACh (Herrera et al., 1985), and we did measure a massive release of catecholamine (Table 1), we would surely have cap- 

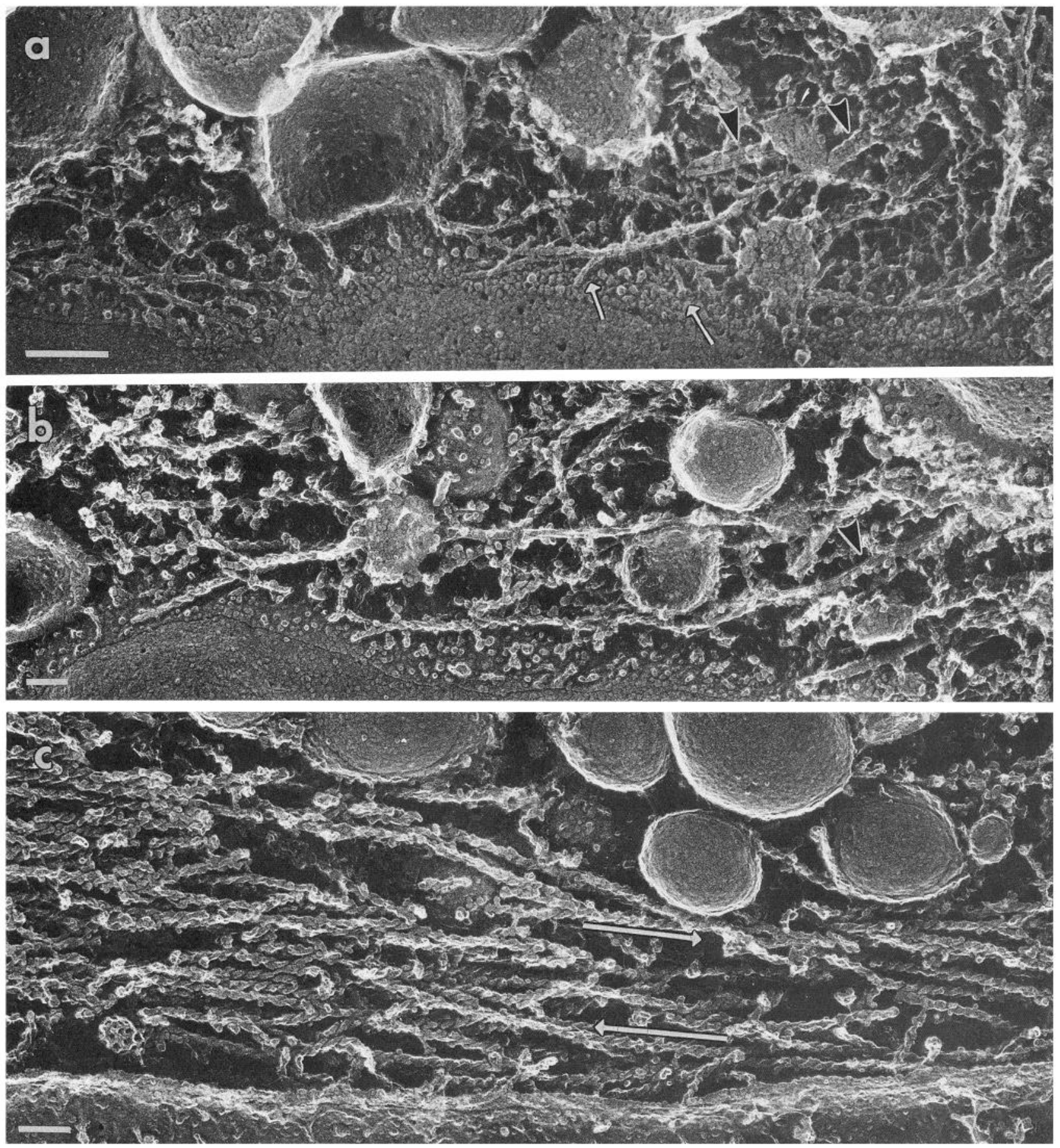

Figure 4. Subplasmalemmal area of digitonin-permeabilized unstimulated chromaffin cells. $a$, Plasma membrane was fractured obliquely, and cytoplasmic surface of the plasma membrane is shown. Nine nanometer filaments are the main component of the subplasmalemmal cytoskeletal network, and sometimes they link to the plasma membrane via thin filaments (arrows). $b$ and $c$, Myosin S1 decoration of digitonin-permeabilized cells. The $9 \mathrm{~nm}$ filaments are decorated by S1, thus proving to be actin filaments. $c$ shows S1 decoration of the subplasmalemmal area in contact with the culture medium. Note the prominent actin bundle, in which the polarity of actin (arrows) is mixed. Plasma membrane is fractured obliquely also in $c$, but the outer surface of the plasma membrane is visible. Some of the microtubules are indicated by arrowheads in $a$ and $b$. Scale bars, $0.1 \mu \mathrm{m}$.

tured changes in these stimulated cell preparations if there had been any notable ones such as a massive disassembly of actin filaments (Cheek and Burgoyne, 1986). However, we found no significant changes in the organization of cytoskeleton after stimulation.

\section{Distribution of actin and exocytotic sites at EM level}

Quick-freezing revealed that there were areas where only few actin filaments were observed beneath the plasma membrane already before stimulation. LM study showed that DBH was 

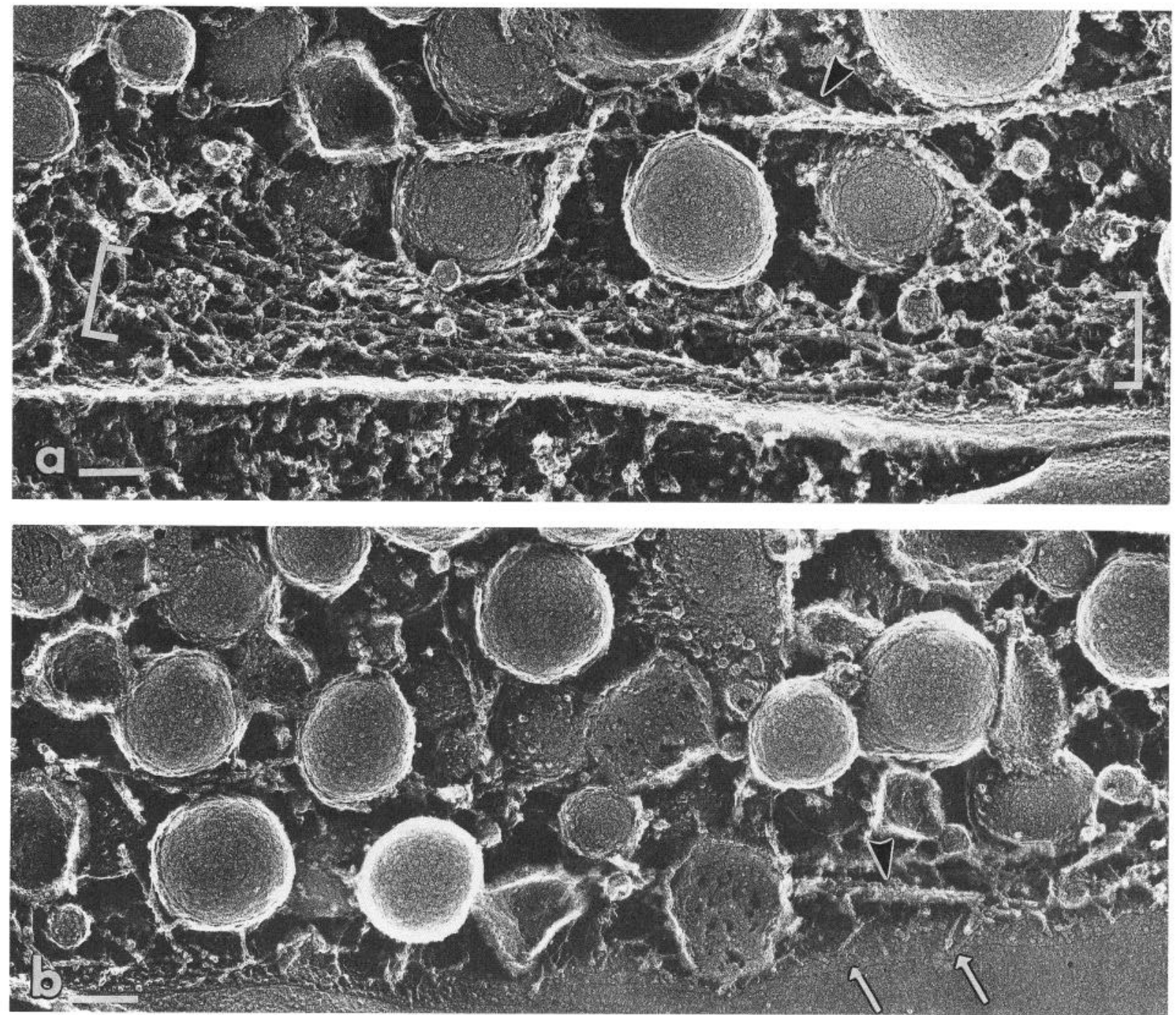

Figure 5. Quick-freeze, deep-etch view of the subplasmalemmal area of chromaffin cells $30 \mathrm{sec}$ after stimulation with $100 \mu \mathrm{M}$ carbachol. The cells were chemically permeabilized before quick-freezing. Plasma membrane is perpendicularly fractured in $a$, while cytoplasmic surface of the plasma membrane is clearly shown in $b$. $a$ shows the area with thick actin networks (bracketed). In $b$, actin filaments are rarely observed, while some thinner filaments are observed just under the plasma membrane (arrows). Microtubules are indicated by arrowheads. Scale bars, $0.1 \mu \mathrm{m}$.

exposed preferentially where F-actin staining is weak after stimulation. Both studies could not find any significant change in cytoskeletal organization after stimulation. From these results, two possibilities must be taken into consideration. One is that exocytosis occurs without any change of actin organization. The other is that small changes in actin organization may occur at each exocytotic site around the moment of the release without changing the total cellular pattern of actin organization. To test

\section{Table 1. Catecholamine secretion from cultured chromaffin cells}

Catecholamine output (\%)

Unstimulated cells

$1.93( \pm 1.74)$

Stimulated cells

$21.94( \pm 8.63)$

Cultured chromaffin cells were incubated for $3 \mathrm{~min}$ at $37^{\circ} \mathrm{C}$ without (unstimulated control) and with (stimulated cells) $100 \mu \mathrm{M}$ carbachol. Catecholamine secretion is expressed as a percentage $( \pm \mathrm{SD})$ of the total amount present in the cells at the beginning of the incubation ( $n=3$ for unstimulated cells; $n=5$ for stimulated ones). these possibilities, it is necessary to analyze the relationship between each exocytosis and the actin localization at its site in detail. We performed double-label immuno-EM on frozen ultrathin sections. In this case, DBH antigens both on the plasma membrane and on the chromaffin granule membrane were labeled by $10 \mathrm{~nm}$ gold particles.

In unstimulated cells, the bulk of $5 \mathrm{~nm}$ gold labeling for actin localized in a continuous band along the inner perimeter of the plasma membrane (Fig. 6a,b). Although the plasma membranes are perpendicularly sectioned, the actin layer is much thicker in Figure $6 a$ than in Figure $6 b$. DBH (10 nm gold) localized to the chromaffin granules and was not exposed on the plasma membranes before stimulation.

DBH antigen became exposed on the plasma membrane upon stimulation (Fig. $7 a, b$ ). In confirmation of our LM study, most of the DBH exposure on the plasma membrane was observed where actin labeling was weak (Fig. $7 b$ ). In contrast, exposure of DBH on the cell surface was rarely found where the cortical actin zone was relatively thick and continuous (Fig. 7c). We 

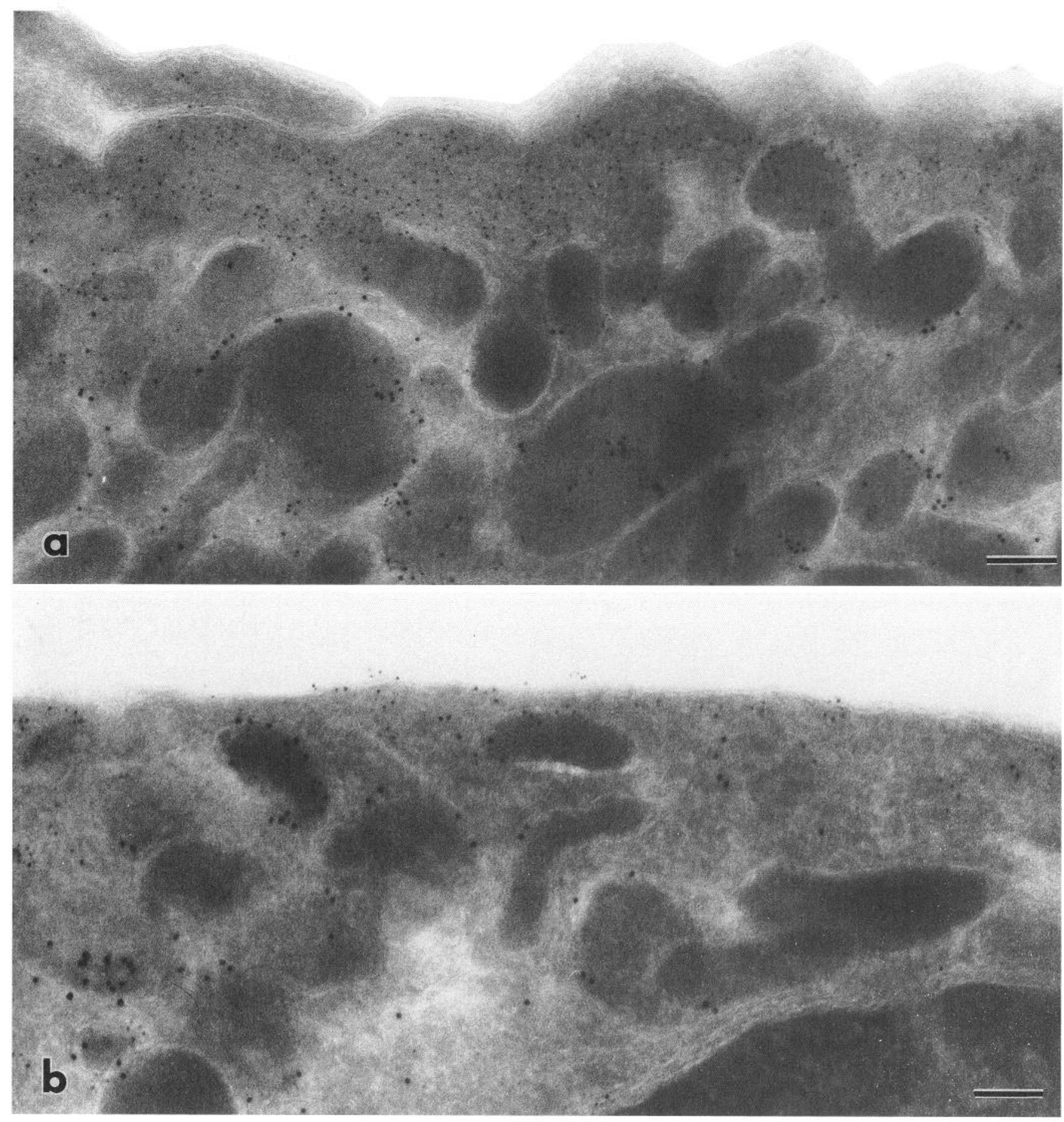

Figure 6. Double-label immunogold-EM of chromaffin cells before stimulation. Anti-actin antibody was followed by $5 \mathrm{~nm}$ colloidal gold-conjugated second antibody. Anti-DBH antibody was followed by $10 \mathrm{~nm}$ colloidal gold-conjugated second antibody. $a$, A continuous thick band of actin labels is observed in the subplasmalemmal area. In $b$, actin labels under the plasma membrane are fewer and secretory granules were closer (but not attached) to the plasma membrane. However, DBH is not expressed on the plasma membrane in either $a$ or $b$. Scale bars, $0.1 \mu \mathrm{m}$.

counted the number of $10 \mathrm{~nm}$ and $5 \mathrm{~nm}$ gold particles along the plasma membrane (see Materials and Methods) and classified the plasma membrane areas according to the DBH and actin label intensity. Table 2 shows that $14.4 \%$ of the actin-thin areas $(0-2$ labels $/ 0.2 \mu \mathrm{m})$ revealed intense DBH labels on the plasma membrane. In contrast, only $2 \%$ of the actin-thick areas (>11 labels $/ 0.2 \mu \mathrm{m}$ ) had heavy anti-DBH gold labelings on the plasma membrane. This tendency in the correlation between actin and DBH labels was statistically significant at the $0.1 \%$ level according to the $\chi^{2}$ test of independence. In immunocytochemistry, there is a possibility that the labeling efficiency depends on the thickness of each section. Nevertheless, the relationship between two labels can be estimated because these two labels were always compared in local area as small as 0.2 

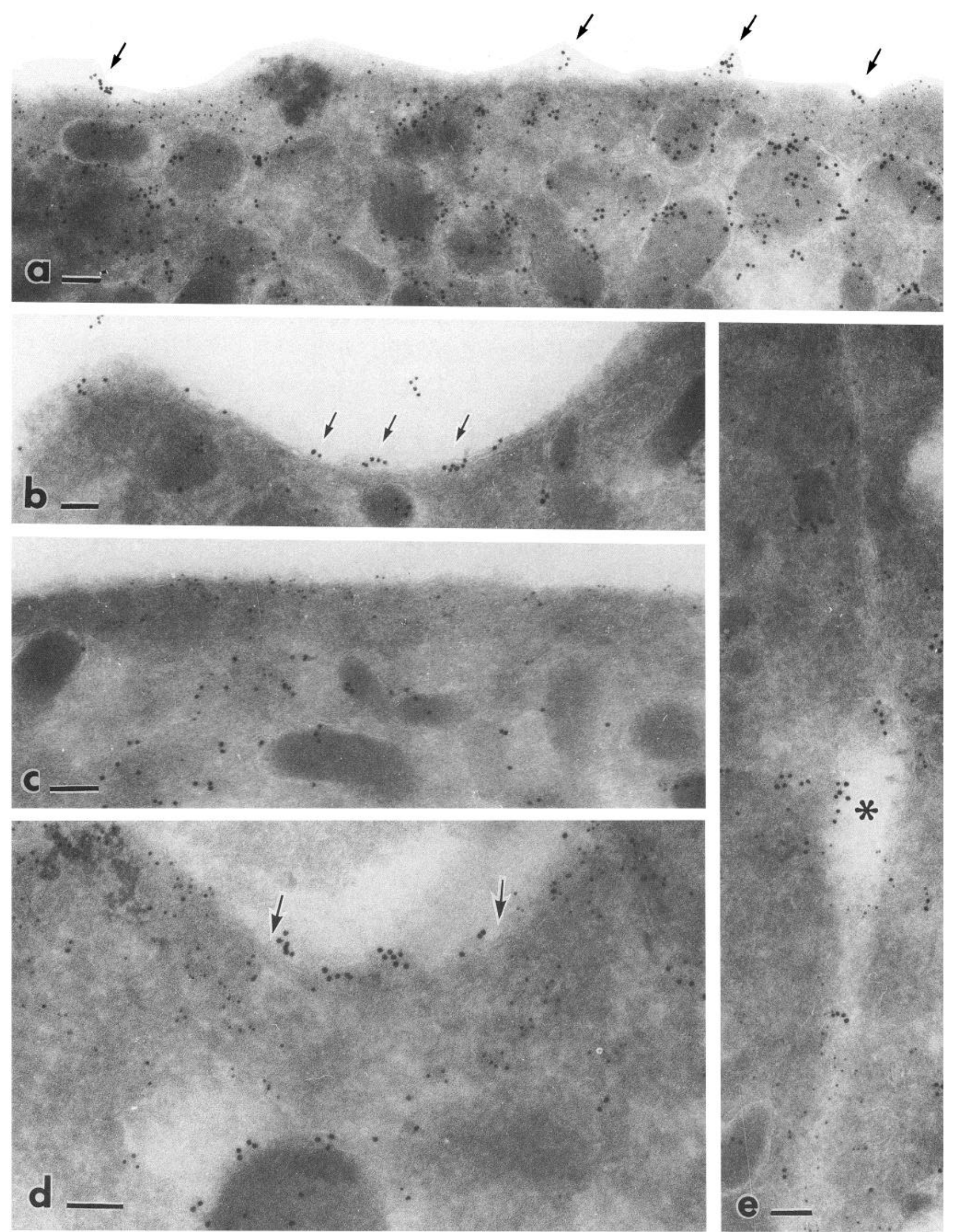

Figure 7. Double-label immunogold-EM of chromaffin cells $30 \mathrm{sec}$ after stimulation. Gold particles represent actin and DBH localization (5 and $10 \mathrm{~nm}$, respectively). $a, \mathrm{DBH}$ is exposed on the plasma membrane (arrows) after stimulation. Subplasmalemmal actin band is disorganized and 
$\mu \mathrm{m}$. Furthermore, we examined the sections with similar thickness, and the results were in accord with the LM study.

When DBH was exposed on the plasma membrane under which actin labels were relatively intense, the actin band was often disorganized and disrupted at the exposed sites (Fig. 7a). This tendency is clear in Figure $7 d$, in which cortical actin labels were disrupted where DBH label is exposed on the plasma membrane (arrows). Because these disruptions of the actin labels were not observed in unstimulated cells, this might suggest a reorganization of actin cytoskeleton associated with exocytotic secretion.

When DBH labels were exposed on the plasma membrane in contact with another cell, they showed a tendency to accumulate and form a lumen (Fig. 7e).

\section{Discussion}

In neurons and neuroendocrine cells, transmitters and hormones are released by exocytosis upon stimulation. However, the molecular mechanism of this process is still unknown. Recently, considerable work has been undertaken on the role of cytoskeleton in regulating secretion from chromaffin cells. The assumption underlying these studies is that the actin-based cytoskeleton between plasma membrane and secretory granules could represent a physical barrier to the movement of secretory granules to the plasma membrane for exocytosis (Aunis and Bader, 1988). The entry of calcium upon stimulation would disrupt the granule-cytoskeleton linkage and also dissolve the actin-based barrier, allowing apposition of the granules and plasma membrane for exocytosis. Several schematic models have been proposed (Trifaro and Fournier, 1987). Although these models are appealing, a detailed analysis of the cytoskeletal organization of chromaffin cells before and after stimulation at the EM level was still required. In this study, we examined the cytoskeletal organization of chromaffin cells and its relationship with exocytotic sites precisely in order to test the above assumption.

We examined the chromaffin granule-cytoskeleton linkage by quick-freezing to test whether chromaffin granules are embedded in the cytoskeletal lattice in the inner cytoplasm. Actin filaments were rarely observed in these areas (Figs. $3 b, 5 a, b$ ), which was also confirmed by rhodamine-phalloidin staining (Fig. 1). The granule-microtubule linkages were observed (Fig. 3d), but microtubules seemed to be fewer than the numerous granules. They may play a role in transporting some of the granules rather than in trapping them all (Vale, 1987; Hammerschlag and Brady, 1988; Hirokawa et al., 1989b). Granules were also linked with each other via fine filaments (Fig. $3 a$ ), but this linkage was not frequent. Thus, the filamentous structures are not well developed in the inner cytoplasm where most of the secretory granules exist.

In subplasmalemmal areas, actin filaments running parallel to the plasma membrane were the main component of the cortical membrane-cytoskeleton (Fig. 4b). The thickness of the cortical actin layer was not uniform. To examine the relationship

\begin{tabular}{|c|c|c|c|c|}
\hline \multirow{2}{*}{$\begin{array}{l}\text { Actin } \\
\text { labels }\end{array}$} & \multicolumn{3}{|c|}{ DBH labels } & \multirow[b]{2}{*}{ Total } \\
\hline & $0-2$ & $3-6$ & $7+$ & \\
\hline $0-2$ & 201 & 54 & 43 & 298 \\
\hline $3-10$ & 206 & 45 & 16 & 267 \\
\hline $11+$ & 120 & 19 & 4 & 143 \\
\hline Total & 527 & 118 & 63 & 708 \\
\hline
\end{tabular}

To analyze the relationship between actin and DBH labels in double-label immuno-EM of chromaffin cells $30 \mathrm{sec}$ after stimulation with $100 \mu \mathrm{m}$ carbachol, plasma membranes were divided into $0.2-\mu \mathrm{m}$-long sections, in which the number of actin labels ( $5 \mathrm{~nm}$ gold particles) beneath the plasma membrane and the number of DBH labels (10 $\mathrm{nm}$ gold particles) on the plasma membrane were counted; 708 sections were classified into nine groups.

between cortical actin organization and exocytotic activities, we used DBH as a marker for exocytosis (Wildman et al., 1981; Lingg et al., 1983). Because membrane recycling in these cells is much slower than in nerve terminals (Patzak and Winkler, 1986), most of the DBH exposed $30 \mathrm{sec}$ after stimulation may well be regarded as remaining in the neighborhood of the original exocytotic sites. The cortical actin band tended to be sparse at exocytotic sites after stimulation at LM and EM level. We used anti-actin antibody, which recognizes both $\mathrm{F}$ - and $\mathrm{G}$-actin at EM level, while we used rhodamine-phalloidin, which recognizes only filamentous actin at LM level. Presumably, because filamentous actin presents antigen sites in very concentrated form compared with G-actin, which may easily diffuse in the cytoplasm, most of the concentrated labels for actin may represent $\mathrm{F}$-actin. These results at LM and EM levels suggested that a thick actin layer might be a barrier to secretion after stimulation. However, it should be noted that some regions had minimal DBH exposure in spite of the lower actin filament content. Thus, the lower actin filament content in the cortical area may be necessary but not sufficient for the secretion. Some other factors, such as calpactin (Nakata et al., 1990) and GTPbinding protein (Bourne, 1988), might play a key role in determination of the secretion sites.

Despite our efforts to fix or freeze the cells at various points after stimulation in quick-freezing as well as in immunocytochemistry samples, we did not detect any massive dissolution or disruption of the cortical cytoskeleton. This finding suggests that massive synchronized reorganization of the cytoskeleton does not need to accompany catecholamine secretion in spite of an elevated intracellular calcium concentration, which can persist for more than $1 \mathrm{~min}$ after stimulation (Cheek et al., 1989). In very special cases, such as when the cells were stimulated immediately after dissociation from the adrenal gland, reduction of phalloidin staining $15 \mathrm{sec}$ after stimulation was reported (Cheek and Burgoyne, 1986). In such cells, actin structures may indeed be very fragile, but cells in 3-7 d cultures, which are commonly used for the study of chromaffin cell secretion, showed no such changes.

disrupted at the exposed sites. $b$, Subplasmalemmal area having few anti-actin labeling. Considerable anti-DBH gold particles are exposed on the plasma membrane and show a patchy distribution (arrows). c; Gold labels for DBH were rarely observed on the plasma membrane under which the anti-actin labeling was relatively dense and continuous. $d$. When exocytotic exposure of DBH occurs in areas with a relatively thick actin band, the band is disrupted at the exocytotic sites. Note that anti-actin gold label is not observed beneath the gold label for DBH on the plasma membrane (arrows). e. Cell-to-cell contact face of the stimulated cells. Actin labels are few. DBH labels are found on the plasma membrane where two plasma membranes form a lumen $(*)$. Scale bars, $0.1 \mu \mathrm{m}$. 
Because we did not compare the same living cell before and after stimulation, there is a possibility that the actin-sparse area is not at the same position before and after stimulation. There is a possibility that the cortical actin organization may oscillate asynchronously after stimulation. However, if it occurs at all, such changes do not induce the overall dissolution of the actin organization before stimulation. These results suggested two possibilities. (1) Exocytotic release occurs only in areas where actin is already sparse before stimulation. Actin reorganization is not required for secretion. (2) Rapid asynchronous, very locally regulated actin reorganizations may occur but need not involve overall change of pattern or disassembly of actin-based cytoskeleton in the whole cell. Although it is not easily answered using statistic LM or EM whether highly localized alternations in actin filament structure are essential for secretion, the latter of the two appears more likely, because we found local disruption of the cortical actin band at DBH-exposed sites after stimulation by double labeling (Fig. $7 d$ ).

In synapses of nerve cells, the subplasmalemmal network of actin and actin-binding proteins is not thick, and their vast reorganization prior to exocytosis seems to be unnecessary, although synaptic vesicles tend to be linked with each other and with cytoskeletal elements such as actin filaments in the cytoplasm via synapsin I (Hirokawa et al., 1989a). These synapsin I and actin linkages appear to regulate the process of transmitter release in synapses by phosphorylation of synapsin I by $\mathrm{Ca}^{2+}$ / calmodulin-dependent protein kinase (Llinas et al., 1985; Hirokawa et al., 1989a). In chromaffin cells, although we found some linkages of unknown nature between granules, they were not frequent. In addition, synapsin I was not found to be associated with chromaffin granules in chromaffin cells (DeCamilli and Navone, 1987). Therefore, the manner of involvement of thin actin layers beneath the plasma membrane in the process of exocytosis could be similar in these two systems, although at the same time they are quite different in terms of the process of exocytosis (Kelley, 1988).

In summary, we have visualized the cytoskeletal organization in resting and agonist-stimulated cultured chromaffin cells. Our quantitative analysis of immunocytochemistry suggests that cortical actin filaments, when dense and making bundles under the plasma membrane, might be a physical barrier to granule secretion after stimulation. These results provide evidence that actin has a regulatory role in the secretory process. However, a massive reorganization of the whole cellular cytoskeleton did not take place after stimulation in spite of abundant secretion. In fact, EM by quick-freezing showed that the cortical actin network is not uniformly constructed and is not a severe barrier in the areas with lower actin content, where exocytosis occurred more frequently. Reorganization of cytoskeleton, if it occurs, might be small and transient around each exocytotic site after stimulation.

\section{References}

Ali SM, Geisow MJ, Burgoyne RD (1989) A role for calpactin in calcium dependent exocytosis in adrenal chromaffin cells. Nature 340 : 313-315.

Anton AH, Sayre DF (1962) A study of the factors affecting the aluminum oxide trihydroxyindole procedure for the analysis of catecholamines. J Pharmacol Exp Ther 138:360-371.

Aunis D, Bader M-F (1988) The cytoskeleton as a barrier to exocytosis in secretory cells. J Exp Biol 139:253-266.

Bernstein BW, Bamburg JR (1989) Cycling of actin assembly in synaptosomes and neurotransmitter release. Neuron 3:257-265.
Bourne HR (1988) Do GTPases direct membrane traffic in secretion? Cell 53:669-671.

Burgoyne RD, Geisow MJ, Barron J (1982) Dissection of stages in exocytosis in the adrenal chromaffin cell with use of trifluoperazine. Proc R Soc Lond [Biol] 216:111-115.

Burgoyne RD, Cheek TR, Norman KM (1986) Identification of a secretory granule-binding protein as caldesmon. Nature 319:68-70.

Cheek TR, Burgoyne RD (1986) Nicotine-evoked disassembly of cortical actin filaments in adrenal chromaffin cells. FEBS Lett 207:110114.

Cheek TR, Jackson TR, O'Sullivan AJ, Moreton RB, Berridge MJ, Burgoyne RD (1989) Simultaneous measurements of cytosolic calcium and secretion in single bovine adrenal chromaffin cells by fluorescent imaging of fura-2 in cocultured cells. J Cell Biol 109:12191227.

DeCamilli P, Navone F (1987) Regulated secretory pathways of neurons and their relation to the regulated secretory pathways of endocrine cells. Ann NY Acad Sci 493:461-479.

Durst DS, Creutz CE (1988) Aggregation of chromaffin granules by calpactin at micromolar levels of calcium. Nature 331:88-91.

Fowler VM, Pollard HB (1982) Chromaffin granule membranc-actin interactions are calcium sensitive. Nature 295:336-339.

Geisow MJ, Burgoyne RD (1987) An integrated approach to secretion. Ann NY Acad Sci 493:563-576.

Hammerschlag R, Brady ST (1988) The cytoskeleton and axonal transport. In: Basic neurochemistry (Siegel G, Albers RW, Agranoff BW, Molinoff P, eds), pp 457-478. New York: Raven.

Herrera M, Kao L-S, Curran DJ, Westhead EW (1985) Flow injection analysis of catecholamine secretion from bovine adrenal medulla cells on microbeads. Anal Biochem 144:218-227.

Heuser JE, Salpeter SR (1979) Organization of acetylcholine receptors in quick-frozen, deep-etched, and rotary replicated Torpedo post synaptic membrane. J Cell Biol 82:150-173.

Hirokawa N, Heuser JE (1981) Quick-freeze, deep-etch visualization of the cytoskeleton beneath surface differentiation of epithelial cells. J Cell Biol 91:399-409.

Hirokawa N, Tilney LG, Fujiwara K, Heuser JE (1982) The organization of actin, myosin, and intermediate filaments in the brush border of intestinal epithelial cells. J Cell Biol 94:425-443.

Hirokawa N, Sobue K, Kanda K, Harada A, Yorifuji H (1989a) The cytoskeletal architecture of the presynaptic terminal and molecular structure of synapsin I. J Cell Biol 108:111-126.

Hirokawa N, Pfister KR, Yorifuji H, Wagner MC, Brady ST, Bloom GS (1989b) Submolecular domains of bovine brain kinesin identified by electron microscopy and monoclonal antibody decoration. Cell 56:867-878.

Kelley RB (1988) The cell biology of the nerve terminal. Neuron 1: $431-438$.

Kumakura K, Ohara M, Sato GP (1986) Real-time monitoring of the secretory function of cultured adrenal chromaffin cells. J Neurochem 46:1851-1858.

Lingg G, Fischer-Colbrie R, Schmidt W, Winkler H (1983) Exposure of an antigen of chromaffin granules on cell surface during exocytosis. Nature 301:610-611.

Livett BG (1984) Adrenal medullary chromaffin cells in vitro. Physiol Rev : 1 103-1161.

Llinas R, McGuinness TL, Leonard CS, Sugimori M, Greengard P (1985) Intraterminal injection of synapsin I or calcium/calmodulin dependent protein kinase II alters neurotransmitter release at the squid giant synapse. Proc Natl Acad Sci USA 82:3035-3039.

Nakata T, Hirokawa N (1987) Cytoskeletal reorganization of the human platelet after stimulation revealed by the quick-freeze, deep-etch technique. J Cell Biol 105:1771-1780.

Nakata T, Sobue K, Hirokawa N (1990) Conformational change and localization of calpactin I complex as revealed by the quick-freeze, deep-etch electron microscopy and immunocytochemistry. J Cell Biol 110:13-25.

Patzak A, Winkler H (1986) Exocytotic exposure and recycling of membrane antigens of chromaffin granules: ultrastructural evaluation after immunolabeling. J Cell Biol 102:510-515.

Patzak A, Bock G, Fischer-Colbrie R, Schauenstein K, Schmidt W, Lingg $G$, Winkler $H$ (1984) Exocytotic exposure and retrieval of membrane antigens of chromaffin granules: quantitative evaluation of immunofluorescence on the surface of chromaffin cells. J Cell Biol 98:1817-1824. 
Perrin D, Langley OK, Aunis D (1987) Anti- $\alpha$-fodrin inhibits secretion from permeabilized chromaffin cells. Nature 326:498-501.

Sontag J-M, Aunis D, Bader M-F (1988) Peripheral actin filaments control calcium-mediated catecholamine release from streptolysin$O$-permeabilized chromaffin cells. Eur J Cell Biol 46:316-326.

Tokuyasu KT (1980) Immunocytochemistry on ultra-thin-frozen sections. Histochem J 12:381-403.

Trifaro J-M, Fournier S (1987) Calmodulin and the secretory vesicle. Ann NY Acad Sci 493:417-434.
Vale RD (1987) Intracellular transport using microtubule-based motors. Annu Rev Cell Biol 3:347-378.

Waymire JC, Bennet WF, Boehme R, Hankins L, Waymire KG, Haycock JW (1983) Bovine adrenal chromaffin cells: high-yield purification and viability in suspension culture. J Neurosci Methods 7:329351 .

Wildmian J, Dewair M, Mathaei H (1981) Immunocytochemical evidence for exocytosis in isolated chromaffin cells after stimulation with depolarizing agents. J Neuroimmunol 1:353-364. 